\title{
Team Software Process (TSPI) Web-Based Support Tool
}

\author{
Nurfauza Jali, Cheah Wai Shiang, Azman Bujang Masli, Yanti Rosmunie Bujang, Abdul \\ Rahman Mat, Suriati Khartini Jali ,Norazian Mohd Hamdan
}

\begin{abstract}
One of the goals as a system or software developer that need to be achieved is to produce a product or system that can be considered as a high-level quality of a product. To help the developer produce a good quality of a product, a tool that will help them make their work easier and efficient is needed. TSPi Tool is one of the methods that can be used by the developer to plan their project, record the project progress, record defect and solve the defects. Currently, FCSIT students who're taking the Software Engineering and Laboratory are using the TSPi Support Tool (Excel Version). However, there are problems exists such as time-consuming which affects the progress of the project. The proposed solution for arising problems was the Team Software Process (TSPi) Tool Web-Based System, a web-based management system to manage and monitor the progress of the product development.
\end{abstract}

Index Terms: team software process, tspi, software engineering course, teamwork, project management, tspi tool system, web-based, software engineering.

\section{INTRODUCTION}

Team Software Process (TSPi) tool is used as a guide for the development teams in producing a high-quality software-intensive system. The TSPi tools mostly used by students especially for those who take Software Engineering and Laboratory subject in Faculty of Computer Science and Information Technology (FCSIT) [1].

Traditionally, the TSPi tools system do exist but only in Excel version which is needed to be downloaded through Morpheus before it can be used. TSPi Tool (Microsoft Excel version) consists of several part which are TSPi instructions, Team member and their roles, SUMP, SUMQ, Task planning, Schedule planning, Week summary, Issue/Risk Tracking Log (IRTL), Issue risk week summary (IRWeek), Defect type and QProfile parameter [2].

However, the current TSPi Tool workbook does not have a database to save and retrieve a data whenever the user wants to do such an operation. Therefore, a precaution method such

Revised Manuscript Received on August 19, 2019.

Nurfauza Jali, Faculty of Computer Science \& Information Technology, Universiti Malaysia Sarawak, Sarawak, Malaysia.

Cheah WaiShiang, Faculty of Computer Science \& Information Technology, Universiti Malaysia Sarawak, Sarawak, Malaysia.

Azman Bujang Masli, Faculty of Computer Science \& Information Technology, Universiti Malaysia Sarawak, Sarawak, Malaysia.

Yanti Rosmunie Bujang, Faculty of Computer Science \& Information Technology, Universiti Malaysia Sarawak, Sarawak, Malaysia.

Abdul Rahman Mat, Faculty of Computer Science \& Information Technology, Universiti Malaysia Sarawak, Sarawak, Malaysia.

Suriati Khartini Jali, Faculty of Computer Science \& Information Technology, Universiti Malaysia Sarawak, Sarawak, Malaysia.

Norazian Mohd Hamdan , Faculty of Computer Science \& Information Technology, Universiti Malaysia Sarawak, Sarawak, Malaysia. as keeping an extra workbook file is needed if in case the excel file might be corrupt or missing. Thus, this paper describes the proposed system, the Team Software Process (TSPi) Tool Web-Based System which intends to overcome the problem.

The rest of this paper is organised as follows. Section 2 illustrates the review of the literature. This review literature

includes the review of TSPi structure and flow, review on the existing system, and a comparison between the existing systems and the Web-Based TSPi System.

Meanwhile, Section 3 discusses the requirement analysis. This section describes the development methodology that will be used for the system which is Rapid Application Development (RAD).

\section{LITERATURE REVIEW}

This section illustrates a review based on similar existing systems and the TSPi Tool Web-Based System. There are two existing systems that have been reviewed namely; Team Software Process (TSPi) and Process Dashboard.

\section{Team Software Process (TSPi) Support Tool}

The TSPi Tool System is mainly developed using Microsoft Excel. This support tool requires Microsoft Excel version 97SR-1 or later version to be used. The TSPi Support Tool helps the team to plan their project, track the project schedule and track the project quality plan. This workbook consist of several forms namely Roles, Program Plan Summary (SUMP), Quality Plan Summary (SUMQ), Size Summary (SUMS), Task Planning Template (TASK), Schedule Planning Template (SCHEDULE), Week Summary (WEEK), Issue/Risk Template Tracking Log (IRTL), Issue Risk Week Summary (IRWeek), Time Recording Log (LOGT), Defect Recording Log (LOGD) and Qprofile Parameter [2]. Figure 1 and Table 1 show the strategy development and planning with the list of forms in TSP process.

Published By:

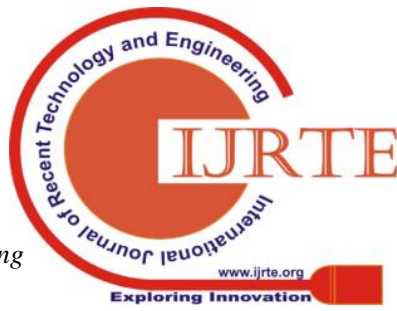




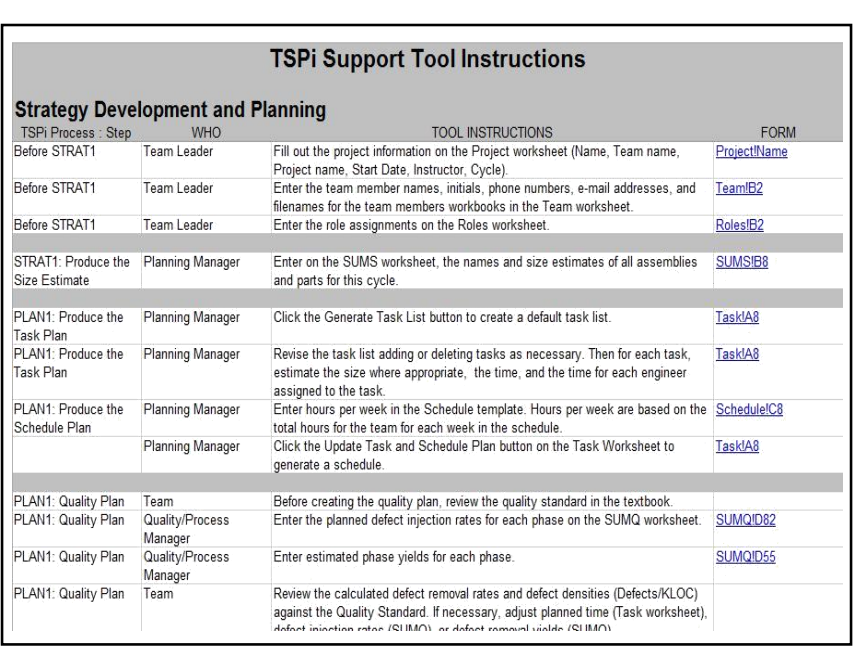

Fig. 1. TSPi Support Tool Front Tab in Excel Version

Table 1. List of forms inside the TSPi support tool workbook and its function from Watt's technical report [2].

\begin{tabular}{|c|c|}
\hline Form Name & Function \\
\hline Roles & $\begin{array}{l}\text { The project team members should } \\
\text { have their own roles and } \\
\text { responsibilities. Each member can } \\
\text { hold one or two roles. Roles } \\
\text { mentioned before are: } \\
\text { 1. Project Manager } \\
\text { 2. Planning Manager } \\
\text { 3. Quality/Process Manager } \\
\text { 4. Support Manager } \\
\text { 5. Test Manager } \\
\text { 6. Process Manager } \\
\text { 7. Implementation Manager } \\
\text { 8. Customer Interface } \\
\text { Manager }\end{array}$ \\
\hline $\begin{array}{l}\text { Program Plan Summary } \\
\text { (SUMP) }\end{array}$ & $\begin{array}{l}\text { To summarise all teamwork which } \\
\text { includes planned and actual size, } \\
\text { planned and actual time in phase, } \\
\text { planned and actual defects injected } \\
\text { by phase and also planned and actual } \\
\text { defects removed by phase. }\end{array}$ \\
\hline $\begin{array}{l}\text { Quality Plan Summary } \\
\text { (SUMQ) }\end{array}$ & $\begin{array}{l}\text { Used to record data of planned and } \\
\text { the actual quality. Data then will be } \\
\text { stored as components, modules, } \\
\text { performance stages, process and } \\
\text { defect removal rate. }\end{array}$ \\
\hline Size Summary (SUMS) & $\begin{array}{l}\text { Used to measure the size of each } \\
\text { product. This form includes a plan } \\
\text { and actual size for each part and } \\
\text { assembly. }\end{array}$ \\
\hline $\begin{array}{l}\text { Task Planning Template } \\
\text { (TASK) }\end{array}$ & $\begin{array}{l}\text { Every completed task should be } \\
\text { recorded and entered in this form. } \\
\text { This form includes the estimation, } \\
\text { planned date, actual hours and actual } \\
\text { date for each tasks. }\end{array}$ \\
\hline $\begin{array}{l}\text { Schedule Planning } \\
\text { Template (SCHEDULE) }\end{array}$ & $\begin{array}{l}\text { This form is used to produce the } \\
\text { team plan. It calculates the planned } \\
\text { value and determines the date when } \\
\text { each the tasks will be completed. }\end{array}$ \\
\hline
\end{tabular}

\begin{tabular}{|l|l|}
\hline Week Summary (WEEK) & $\begin{array}{l}\text { This form is to prepare the weekly } \\
\text { status reports of the project. Each } \\
\text { team member needs to complete this } \\
\text { form every week. Those members } \\
\text { need to show the completed work } \\
\text { last week and plan for the next week } \\
\text { work. }\end{array}$ \\
\hline $\begin{array}{l}\text { Issue/Risk Tracking Log } \\
\text { (IRTL) }\end{array}$ & $\begin{array}{l}\text { To record and monitor project } \\
\text { problems or risks. }\end{array}$ \\
\hline $\begin{array}{l}\text { IssueRiskWeekSummary } \\
\text { (IRWeek) }\end{array}$ & $\begin{array}{l}\text { Record and monitor project } \\
\text { problems and risks weekly. }\end{array}$ \\
\hline $\begin{array}{l}\text { Time Recording Log } \\
\text { (LOGT) }\end{array}$ & $\begin{array}{l}\text { Used to record the time taken for the } \\
\text { development to finish. These include } \\
\text { the assembly and phase for each task, } \\
\text { the date, start time, interrupt time, } \\
\text { stop time and comments. }\end{array}$ \\
\hline
\end{tabular}

\section{Process Dashboard}

Process Dashboard is an open source software which can be downloaded freely. It is a Java-based and can be run on any system with a Java 2 compliant virtual machine [3]. This includes Mac OS, Windows, Linux and Unix. Process Dashboard was developed in 1998 by the United States Air Force.

This software supports the following functionality for the user. The functionalities are planning, data collection, tracking, data analysis, and data export. The overall process of Process Dashboard is shown in Figure 2. From Figure 2 below, it shows that the Process Dashboard has four different processes; Organisation preparation, Launch preparation, Team project launch tasks and Run the project. The processes conducted by 4 different type of organisations; Process Mentor, Program Manager, Team Leader and Team Members.

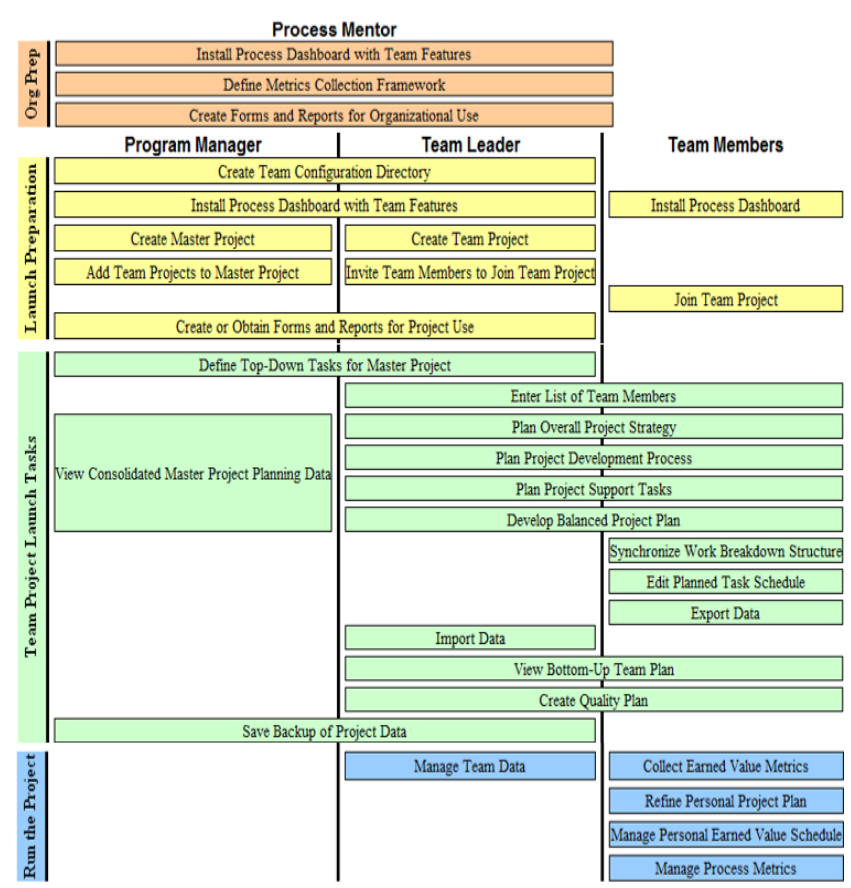

Fig. 2. Overview of Project Dashboard for Team Projects

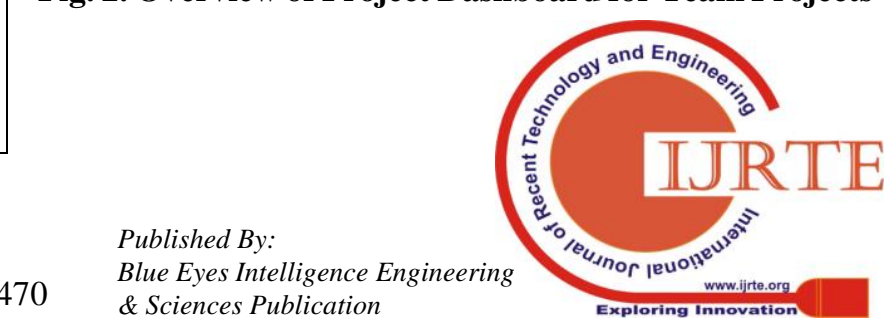


Moreover, the strengths, weaknesses, software and hardware requirements are also identified in this section which is needed in the process of the development. A comparison between the existing systems with the TSPi Tool Web-Based System also being studied as a guide for the development process. The comparisons are being categorized in Table 2 .

Table 2. Comparison of features between the existing system and the Web-based proposed system

\begin{tabular}{|l|c|c|c|}
\hline \multicolumn{1}{|c|}{ Features } & $\begin{array}{c}\text { TSPi Support Tool } \\
\text { Workbook (Excel) }\end{array}$ & $\begin{array}{c}\text { Process } \\
\text { Dashboard }\end{array}$ & $\begin{array}{c}\text { TSPi Tool } \\
\text { System } \\
\text { (Web-Based } \\
\text { proposed } \\
\text { system) }\end{array}$ \\
\hline Web-Based System & $\mathbf{x}$ & $\mathbf{x}$ & $\checkmark$ \\
\hline Free (Open Source) & $\checkmark$ & $\checkmark$ & $\checkmark$ \\
\hline Can store data inserted & $\mathbf{x}$ & $\checkmark$ & $\checkmark$ \\
\hline $\begin{array}{l}\text { Interactive data } \\
\text { visualisation }\end{array}$ & $\mathbf{x}$ & $\mathbf{x}$ & $\checkmark$ \\
\hline $\begin{array}{l}\text { Compatible in all } \\
\text { platform }\end{array}$ & $\checkmark$ & $\checkmark$ & $\checkmark$ \\
\hline Easy to use & $\mathbf{x}$ & $\mathbf{x}$ & $\checkmark$ \\
\hline
\end{tabular}

The system embarks on the following objectives:

- To implement the TSPi Tool which exists in Excel version into a web-based system.

- To design and develop the existing feature of TSPi Tool System, then can automatically calculate a value that has been inserted.

- To improve the TSPi Tool System interfaces so that it becomes more user-friendly and easier to use.

- To create a database so that all the data can be retrieved and stored without worrying, it might lose

This system is expected to produce the following outcome, where student able to; a) use a web-based TSPi Tool System; b) know the status of their project title, and c) Required value is calculated automatically by the system.

\section{METHODOLOGY}

This section recaps about how the system is being developed by following the Rapid Application Development (RAD) [4]. RAD is chosen because this methodology is less emphasis on the planning, rather than that it more focused on the development and the project is intended to be produced in a short time constraint.

RAD is a software development methodology that uses minimal planning which resulting in rapid prototyping. The planning happened while the process of writing the software itself. RAD can develop faster and higher quality through the requirement gathering using workshop or focus group, prototyping, re-use the software component, a rigidly paced schedule that defers design improvement to the next product version and less formality in the review.

RAD has four phases which are requirement/planning stage, system design stage, development stages and cutover stages, but cutover stages will not be covered in this project since the constraint of time and resource limitation.

\section{System Design and Construction}

In this section, it concerns more about the implementation and development of the TSPi Tool Web-Based System. The main purpose of this phase is to design a system that can fulfil user requirement. By using data and information that has been gathered during requirement analysis and system design, it is used as a main reference to implement the component of the system itself. As for this system, it is important to verify the implementation phase to ensure that the system has fulfilled the system specification and requirement that has been gathered during in the previous chapter.

This system has two different users; the System Administrator and the Team itself as shown in Table 3. The different user has restricted access to the system. TSPi Tool Web-Based System will be maintained and managed by the System Administrator.

\section{Table 3. Systems users functions features}

\begin{tabular}{|c|c|}
\hline System Administrator functions & System User functions \\
\hline $\begin{array}{l}\text { - View all user details } \\
\text { - View the TSPi Forms } \\
\text { - Delete the TSPi Forms } \\
\text { - Register new user into the } \\
\text { system } \\
\text { - Delete user in the system } \\
\text { - Approve/Disapprove project } \\
\text { title }\end{array}$ & $\begin{array}{l}\text { - View the TSPi Forms } \\
\text { - Update/edit the TSPi } \\
\text { Forms } \\
\text { - Delete the TSPi Forms } \\
\text { - Register into the } \\
\text { system } \\
\text { - View the team's } \\
\text { profile }\end{array}$ \\
\hline
\end{tabular}

Features of the system shown in Table 4 below:

Table 4. TSPi Web-based Support System features

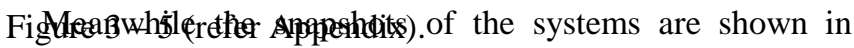

\begin{tabular}{|l|l|}
\hline System Features & Description \\
\hline Sign Up & The user is allowed to register into the system. \\
\hline Login page & $\begin{array}{l}\text { The user needs to have username and password to } \\
\text { login in to use this system. }\end{array}$ \\
\hline Change password & The user is allowed to change their password. \\
\hline Add project details & $\begin{array}{l}\text { The user (Team) are allowed to add their project } \\
\text { title } \\
\text { and project description into the system to be } \\
\text { reviewed by their instructor. }\end{array}$ \\
\hline Approved/Disapprove & $\begin{array}{l}\text { The user (System administrator) able to } \\
\text { approve/disapprove teams' project. }\end{array}$ \\
\hline View project status & $\begin{array}{l}\text { The user (Team) is allowed to view the projects' } \\
\text { status. }\end{array}$ \\
\hline Enter TSPi forms & $\begin{array}{l}\text { As being mentioned in the introduction section, } \\
\text { there are several forms that exists in this system. } \\
\text { User (Team) are allowed to enter the system as } \\
\text { long as they are log into the system. }\end{array}$ \\
\hline Edit TSPi forms & $\begin{array}{l}\text { The user (Team) is allowed to edit their form that } \\
\text { has been filled in and it will replace the old data } \\
\text { with the new data. }\end{array}$ \\
\hline Delete existing forms & $\begin{array}{l}\text { The user is allowed to delete the existing form. } \\
\text { once the form has been submitted to the database. }\end{array}$ \\
\hline
\end{tabular}

There are 2 out of 8 Forms Calculation involved in this system are listed in Table 5 below.

Published By:

Blue Eyes Intelligence Engineering

\& Sciences Publication 
Table 5. Formulas implemented in the forms

\begin{tabular}{|c|c|c|}
\hline No & $\begin{array}{l}\text { Form } \\
\text { Name }\end{array}$ & Default Value or Calculated Value \\
\hline 1 & $\begin{array}{l}\text { TASK } \\
\text { Form }\end{array}$ & $\begin{array}{l}\text { Total Plan Hours (TPH) } \\
\text { TPH = Add all TPH values } \\
\text { Total Actual Hours (TAH) } \\
\text { TAH = Add all TAH values } \\
\text { Estimated Hours(EH) } \\
\text { EH = Size/Rate } \\
\text { Planned Value (PV) } \\
\text { PV = (Plan hour each task / Total plan hours) * } \\
100 \\
\text { Cumulative Planned Value (CPV) } \\
\text { CPV = CPV + PV } \\
\text { Earned Value (EV) } \\
\text { EV = (Actual hour each task / Total actual hour) } \\
* 100 \\
\text { Cumulative Earned Value (CEV) } \\
\text { CEV = CEV + EV }\end{array}$ \\
\hline \multirow[t]{2}{*}{2} & \multirow{2}{*}{$\begin{array}{l}\text { WEEK } \\
\text { Form }\end{array}$} & Weekly Data \\
\hline & & $\begin{array}{l}\text { - Schedule hours for this week } \\
\text { Hours = Plan hours this week / Actual hours } \\
\text { this week } \\
\text { - Schedule hours this cycle to date } \\
\text { Hours = Plan hours this cycle / Actual hours } \\
\text { this cycle } \\
\text { - } \quad \text { Earned value for this week } \\
\text { EV = Plan EV this week / Actual EV this week } \\
\text { - Earned value for this cycle to date } \\
\text { EV = Plan EV this cycle / Actual EV this cycle } \\
\text { - To-date hours for tasks completed } \\
\text { To-date hours = Plan to-date hours / actual } \\
\text { to-date hours } \\
\text { To-date average hours per week } \\
\text { To-date average = Plan to-date average / } \\
\text { Actual to-date average }\end{array}$ \\
\hline
\end{tabular}

\section{Testing and Evaluation}

This section describes in detail about the testing process for the system that is being implemented in this project. The testing process is divided into two main testing which is functional and non-functional testing.

Functional testing concerned with the functional requirement and covers how well and how accurate the system is functioning [5]. It will be done by both the developer and the end user. A User Acceptance Test (UAT) documentation will be prepared for the tester, and the outcome should be the same as the expected result written in the UAT documentation. The UAT here means the test case documentation. The test case is a kind of documentation which is used to record all result of tested functionalities of the developed system. This is to ensure that the system works perfectly and has met the entire stated requirement before it can be published to the outside. It consists of several criteria such as the test case ID, objective of the test, expected result, actual result, the status of the test, the severity of defects and comments.

If the user did not get the accurate output after the execution, meaning that the system has some bugs. The bugs are logged in a testing document and need to be attached to relevant comments.

Besides, the external testing will be carried out to test whether the system features has fulfilled the client's requirement and thus the client itself does this type of testing.
If the client has something in their mind or the system does not fulfil what they want, then they can comment, and the comments will be used to track progress and issues during UAT process [6].

Debono [7] asserted that non-functional testing concerned about the non-functional requirement of the system. It demonstrates how well the product behaves as opposed to simply what the product does. This testing includes performance testing and security testing. For the performance testing, it is mainly based on the loading time of a web browser to access the system. Therefore, different types of browser such as Google Chrome, Mozilla Firefox and Internet Explorer are used to test the system. Furthermore, a different security role needs to be tested to ensure that an authenticated user can access the system.

The respondents were selected from the previous Software Engineering students who have experienced using the existing tool since they already know how the software tool works. After the students tested the system, they also are required to enter a form to give their feedback. After the testers filled in the form, a chart is created to summarise their response easily to be viewed.

Bar graph in Figure 7 shows the 40 number of respondents and their preferred information for the developed system by using a Likert Scale method. From the bar graph, it shows that 35 respondents choose excellent since the developed system worked efficiently. Meanwhile, all the respondents believed that the system take shorter time to be filled in and have chosen excellent for this. The developed system is also more user-friendly and excellent and were agreed by 30 respondents. There were 40 respondents saying that there is no possibility of losing data and marked their choices as excellent. Since the system worked the way they want, 25 respondents marked for excellent and only 15 respondents marked very good. Besides, 30 respondents chose excellent because the system helps them to be more effective.

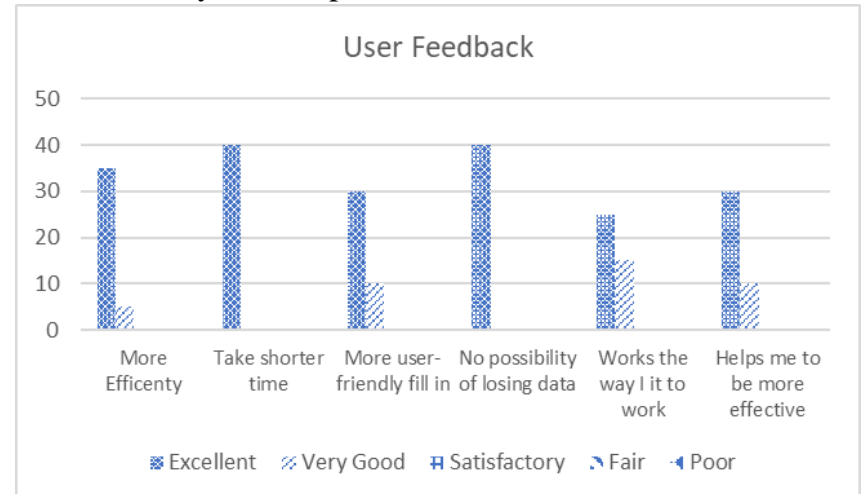

Fig. 6. End-user feedback for the developed system

Meanwhile, all the respondents are satisfied with the system and marked the form as excellent to express their satisfaction. Figure 7 below shows the picture of students during the Software Engineering Laboratory course session who have used both excel and web-based TSPi tool.

Published By: 


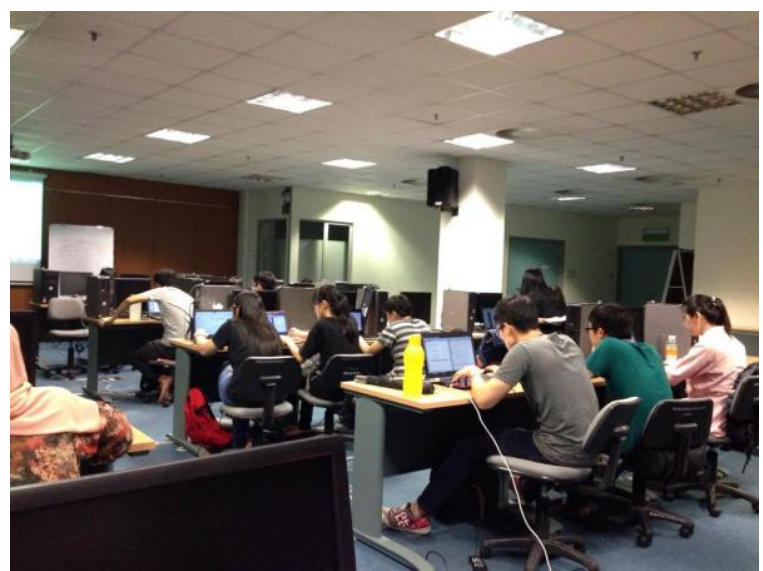

Fig. 7. Students performing the user testing

\section{CONCLUSION}

This article presents an overview of TSPi structure, flow, and discussed the review on existing system as well as a review for the web-based proposed system. The comparison between the existing systems and the proposed system is also being mentioned in this article. This system will replace the Excel-based by providing a new platform for the students to use the "Team Software Process (TSPi) Tool Web-Based System". Therefore, enable the lecturer to approve/disapprove the teams' project title. Other features which include the ability for each teams (students) to know the status of their project evaluation through the system. All data that has been submitted are being stored inside the database and forms can be printed by the team easily. However, there are challenges towards this system which it cannot auto-generate the graph and the users are not notified for any submission. Therefore, it is recommended to enhance the functionality of the developed system where it can auto-generate the graph and notified the user for submission that has been done in future works.

\section{APPENDIX RESULTS}

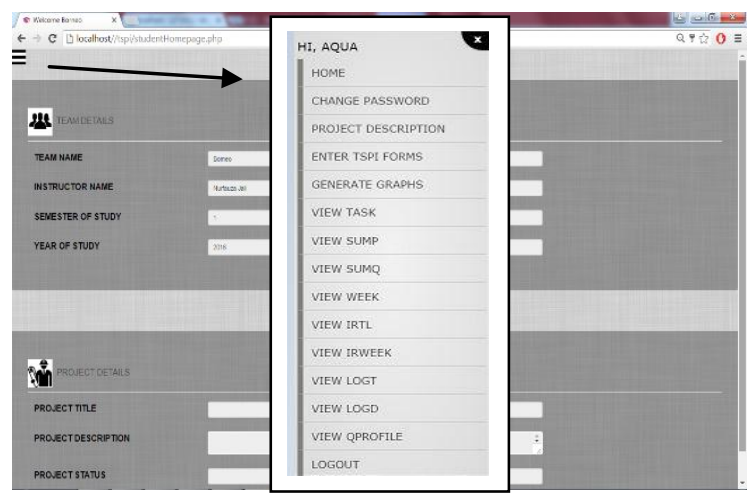

Fig 3.0 Home page for team user

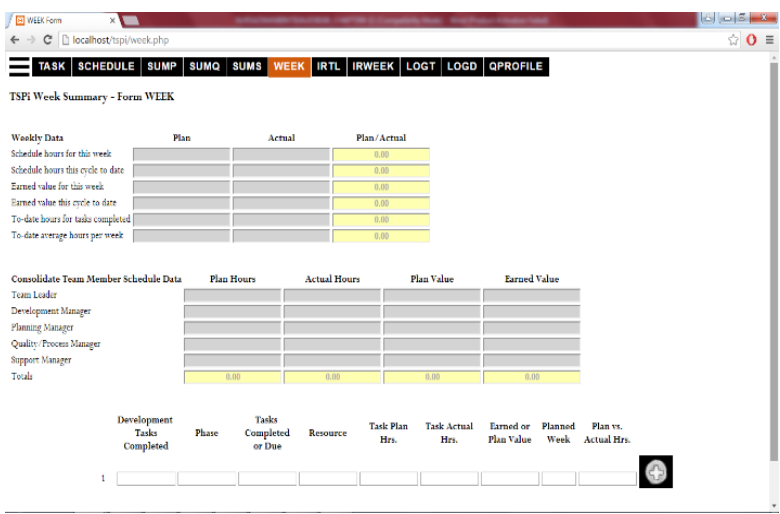

Fig. 4.0 WEEK Form

\section{ACKNOWLEDGMENT}

The authors thank the reviewers for providing the useful and rigorous comments; these significantly contributed to improving the quality of the paper. They are grateful to Miss Nursazwani Asmadiah for developing the TSPi Support system.

\section{REFERENCES}

1. Jali, N., Masli A.Z, Cheah, W.S., Bujang, Y. R., Mat, A.R, Hamdan, A.H. (2017) The Adoption of Agile Software Methodology with Team Software Process (TSPI) Practices in the Software Engineering Undergraduate Course. Journal of Information Technology in Asia (JITA) 7 (1).

2. W. S. Humphrey. (2010) Introduction to Team Software Process, Canada: Addison-Wesley.

3. "The Software Process Dashboard Initiative," Tuma Solution, [Online]. Available: http://www.processdash.com/home. [Accessed 12.01.2018].

4. Nashawaty, P. (2015). Rapid Application Development New Jersey: John Wiley \& Sons, Inc.

5. "About Functional Testing," [Online]. Available: https://support.smartbear.com/viewarticle/71490/. [Accessed 05.03.2018].

6. Hambling, B., van Goethem, P. (2013) User Acceptance Testing: A step-by-step guide. BCS, The Chartered Institute for IT. [Accessed 10.03.2018].

7. Debono, M (2012). Functional vs Non Functional Testing. [Online].

Available: http://www.reqtest.com/blog/functional-vs-non-functiona 1-testing/ [Accessed 10.03.2018].

\section{AUTHORS PROFILE}

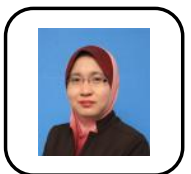

Nurfauza Jali is a senior lecturer at the Faculty of Computer Science and Information Technology, Universiti Malaysia Sarawak (UNIMAS). She received her MSc in Science Computer (Real Time Software Engineering) from Universiti Teknologi Malaysia (UTM) Her research interest focuses in Requirement Engineering, Software Design Pattern and Object Oriented Design. 
Cheah WaiShiang is a senior lecturer from Faculty of Computer Science \& IT, UNIMAS. He graduated with $\mathrm{PhD}$ in software engineering, The Melbourne University. His research is agent oriented modelling and simulation.

Azman Bujang Masli is presently working as a senior lecturer at Faculty of Computer Science and Information Technology in UNIMAS. He received his $\mathrm{PhD}$ from The Sheffield University, UK in 2011. His research area interest includes software engineering, formal specification and verification.

Yanti Rosmunie Bujang is presently working as a senior lecturer at UNIMAS. She received her PhD from International Islamic University Malaysia (IIUM). Her research interests including software testing, community services, ethics in Information Technology and Internet

Safety.

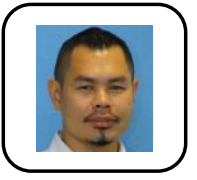

Abdul Rahman Bin Mat is a lecturer for Software Engineering programme at UNIMAS. He received his master's in computer science and Engineering in Aizu University (Japan) at year 2005. He had more than 10 years' experience in research and development (R\&D). The area of interests includes requirement analysis and specification, knowledge-based system, formal method, and software testing.

Suriati Khartini Binti Jali is presently working as a senior lecturer at UNIMAS. She received her PhD from Coventry University. Her research interests in Serious Game, Game-based Learning, Web/Mobile-based design and application, Human-Centered Computing, User Interaction (UI) and User Experience (UX)

Norazian Mohd Hamdan is presently working as a lecturer at UNIMAS. She received her Master of Science (Computer Science) in Universiti Teknologi Malaysia (UTM). Her research interests in Software Engineering, Artificial Intelligence and Software Requirements. 